\title{
Oscar del Barco editor: la construcción de una política de la teoría en Ediciones Caldén
}

\section{Oscar del Barco Editor: The Construction of a Politics of Theory at Ediciones Caldén}

\begin{abstract}
Resumen
A partir del análisis de la colección "El hombre y su mundo", dirigida por Oscar del Barco en Ediciones Caldén (Argentina) entre 1967 y 1976, este trabajo busca dar cuenta de las relaciones entre teoría y edición en Argentina durante el período señalado. Puntualizamos dos aspectos que se articulan entre sí y en torno a los cuales buscamos proponer el modo en que del Barco urde, con su tarea de editor, traductor, compilador y ensayista, una política de la teoría; estos aspectos contemplan: 1) la construcción de una poética editorial donde la traducción de autores de la teoría política, el estructuralismo y el postestructuralismo convive y configura una biblioteca específica mediada por textos críticos del editor; 2) una práctica editorial en términos de "contrabando" en tanto utilización de revistas extranjeras como fuente y referencia para la conformación de libros pequeños sin cesión de derechos de autor, contratos o permisos editoriales. En la articulación de los dos aspectos señalados, interesará destacar el carácter performativo de la relación entre teoría y edición, ya que "El hombre y su mundo" pone a circular libros según prácticas y materialidades que actúan aquello que los textos proponen.
\end{abstract}

Palabras claves

Teoría; edición; años 70; Literatura; Oscar del Barco; postestructuralismo.

\begin{abstract}
In this paper, we look at how theory and publishing practices were intertwined in Argentina between 1967 and 1976. We do so by analyzing "El hombre y su mundo" ["The Man and His World"], a collection of books directed by Oscar del Barco for Ediciones Caldén (Argentina) during that period. We hold that del Barco's multifaceted work as editor, translator, compiler,
\end{abstract}


and essayist, created a politics of theory, focusing on two interrelated aspects: 1) a poetics of publishing, with translations of works by political theorists, structuralist and poststructuralist thinkers coming together in a unique collection mediated by del Barco's critical texts, and 2) a "smuggling" publishing practice -as texts were selected, translated and shaped into small books from foreign magazines with no copyright permission. We see a performative force in such interrelation of theory and publishing strategies, as "El hombre $y$ su mundo" made available books through practices and materialities that acted upon what those very books were calling for.

Keywords theory; publishing; 70's; Literature; Oscar del Barco; post-structuralism.

\section{Contrabandistas y plebeyos: la edición de "teoría" en la Argentina de los años 70}

En una conversación con Jorge Wolff a propósito de los telquelismos ${ }^{1}$ latinoamericanos durante los años 60 y 70, Germán García -integrante de la revista argentina Literal (1973-1976) y autor de la novela Nanina-, se detiene a pensar la historia de la teoría desde un ángulo editorial, y postula ese vínculo en términos de "contrabando": "la cultura argentina es tan de contrabandistas y mentirosos que todos los autores que nosotros hemos difundido en castellano han sido editados por mejicanos y no por nosotros. Nosotros editamos 'dossier'. Entonces, por ejemplo, todo Lacan está editado en Méjico, pero descubierto en Buenos Aires” (García en Wolff, 264). Con este comentario, García caracterizaba un modo fragmentario de la circulación de la teoría en Argentina. El "contrabando" cifraría, así, los desplazamientos de piezas arrancadas y repuestas en otras series o colecciones, o bien un tráfico de minucias, como quien busca en lo breve y lo pequeño pasar desapercibido ante los controles de la ley. La imagen de "contrabandistas y editores de dossier" puede pensarse, a su vez, junto con la lectura que hace Diego Peller

1 Con "telquelismos latinoamericanos", Jorge Wolff designa no solo la influencia de la revista francesa Tel Quel, que había encarnado de manera paradigmática el "llamado 'Pensamiento "68" (Wolff 11) al proponer una articulación entre "experimentación estética y teórica + revolución política" (11), sino también una red de lecturas y conexiones en torno a la teoría que tuvieron un impacto decisivo en la "nueva crítica" literaria argentina y brasileña de los años '60 y '70. 
acerca de las pasiones teóricas de los '70, cuando apunta hacia ciertos usos "plebeyos" de la teoría en Argentina (229), con los cuales propone desarticular la instalada dicotomía entre "radicalización política" y "modernización estética y teórica" que señalaría una "escalada ascendente" de la primera en detrimento de la autonomía del campo cultural. Esos usos plebeyos son usos impertinentes, fragmentarios y situados, que tanto críticos como escritores hacen de la teoría en lengua extranjera o traducida, guiados más por sus propios intereses, que por la voluntad enciclopédica que supondría dar cuenta de un sistema de pensamiento completo. Así, "lo plebeyo" agrega un matiz de sentido a la circulación contrabandista porque inserta lo fragmentario en el horizonte de las lecturas, según el armado de una biblioteca específica y local donde convivían nombres cuya conjunción resultaría conflictiva en la cultura de origen.

"Contrabandistas" y "plebeyos" de la teoría son dos figuras que nos permiten una aproximación al catálogo de Ediciones Caldén -fundada por José Luis Mangieri en 1967-, y en particular a la colección "El hombre y su mundo", a cargo de Oscar del Barco hasta el cierre de la editorial en 1976 -año que coincide con el exilio de este último. La colección estuvo conformada principalmente por libros que reunían breves artículos traducidos con los cuales se armaba un volumen. Muchos de ellos eran tomados de la revista francesa Tel Quel con pocos meses de diferencia desde su primera aparición; del Barco cuenta que lo hacían sin haber establecido un contacto con los autores o responsables de la publicación y agrega: "nosotros, este es el punto, éramos LADRONES, ¡no teníamos ni pagábamos ni un peso". ${ }^{2}$ En ese sentido, a la idea inicial del contrabando según García, se le agrega la dimensión material del "no-pago", la literalidad del robo como modo de construcción del catálogo. Por otra parte, esa dimensión de la teoría como "dossier" más que como biblioteca de Obras Completas, y que se trama con el acto de "robar", puede ser repensada en las relaciones entre prácticas editoriales librescas y prácticas

2 Entre enero y abril de 2021 mantuvimos una entrevista vía mail con Oscar del Barco en la que comentando algunas de las inquietudes consultadas. A partir de acá, ese intercambio será citado como "entrevista con la autora". Las marcas de signos, mayúsculas, guiones, o yuxtaposiciones acumuladas de sintagmas son transcripciones no modificadas del original. 
editoriales revisteriles, es decir, en el flujo constante de textos que van de la revista al libro, y libros que circulan con materialidades semejantes a las de una revista, por su precio, su encuadernación y cierto carácter fascicular.

En cuanto al objeto de interés de la colección, fue la teoría -a secas, sin atributo disciplinar- la que estructuró el conjunto de autores que la integraron; si bien una cantidad significativa de textos publicados muestra un interés específico por lo que llaman "ciencia de la escritura" (que podríamos pensar como un momento central de la teoría literaria), esto se articula, en los mismos textos, con la afirmación de que la teoría "unifica pluralidades", y por lo tanto es el "pensamiento teórico" el que puede contrariar la dominación ideológica que se encarna en los "eclecticismos". ${ }^{3}$ Este aspecto agrega una segunda capa de sentido en torno a la imagen del contrabando porque se vincula con el material publicado por la editorial. Dado que la "ciencia de la escritura" buscaba "hacer surgir la textualidad" (Sollers 123), entendiendo por esto último un cuestionamiento a la cultura del libro y la literatura como "acumulación arqueológica" y "propietaria" del saber (Sollers), poner en movimiento una biblioteca del "pensamiento teórico" a partir de textos breves, pirateados y extraídos sin mayores justificaciones de su contexto de publicación original, parece una forma de materializar la dimensión performativa de dicha ciencia de la escritura.

Traficantes de textos por lo que no pagan, y armadores de una colección de teoría sin los ribetes publicitarios de las Obras Completas o el enganche de libros

3 Textos de Philippe Sollers, Roland Barthes, Julia Kristeva -vinculados a la revista Tel Quel- se centran en la necesidad de pensar la teoría como un lenguaje que evita los eclecticismos que derivarían en la metafísica de la ideología dominante. Como los concretos de los años 40 y 50 , Barthes planteaba, en la entrevista que abre el volumen titulado Literatura, politica y cambio - de la cual no se indican referencias y tampoco el nombre completo del entrevistador o entrevistadoraque teoría "no puede confundirse con la abstracción; por lo tanto no se opone a lo concreto" (Barthes, 1976, 13), y que se trata de "un discurso que se vuelve sobre sí, un lenguaje que se vuelve sobre sí - y esta es su marca distintiva". A continuación se lee, por la misma persona que entrevista, a Philippe Sollers, quien dice: "sin ella [la teoría] se vuelve al empirismo más completo o al positivismo, vale decir, que se recae en los residuos de la ideología dominante, no pensada, de la burguesía. Vale decir, en la repetición pura y simple de criterios representativos o en una errancia ideológica caracterizada por el 'ensayismo"” (Sollers, 1976, 26); y más adelante: “[...] la teoría no es plural. Está encargada de unificar las pluralidades. Se hace pluralmente pero no es plural. En tal caso sería un eclecticismo" (Sollers, 1976, 31). 
"para principiantes", ambos editores contaban por entonces con una trayectoria reconocida en el campo cultural. José Luis Mangieri era desde 1962 el editor de La Rosa Blindada Libros (en un comienzo llamada Ediciones Horizonte, donde "La Rosa Blindada" fue originalmente una colección de poesía) y de la revista homónima que tuvo entre sus integrantes ${ }^{4}$ a autores como Juan Gelman, Andrés Rivera, Cristina Banegas, Estela Canto, León Rozitchner, y a Oscar Díaz -el mítico diseñador de EUDEBA y Centro Editor de América Latina- como diagramador. Oscar del Barco, por su parte, había conformado la dirección y luego el consejo de redacción de la revista Pasado y Presente y las ediciones Cuadernos de Pasado y Presente; era un colaborador intermitente y polémico en la revista Los libros, lector de Georges Bataille y cercano al apoyo de la lucha armada en los '60. 5 Ambos habían sido expulsados del Partido Comunista a fines de la década anterior. ${ }^{6}$ En los dos hay un vínculo fundante con la literatura y con los modos en que esta constituye una experiencia de lo político que desborda los lineamientos de cualquier organización, partido o proyecto. ${ }^{7}$ Así, Ediciones Caldén emerge y se desarrolla en el marco de una serie de relaciones editoriales atravesadas por la política de manera decisiva. En ese sentido, "relaciones editoriales" refiere no solo a una serie de sellos cercanos con los que se interactúa, sino también a diseñadores y traductores compartidos, o bien libros que se anuncian en una editorial y salen en otra; es decir,

4 "El director honorario de la revista era Raúl González Tuñón; los directores responsables -y es una forma de decir-Carlos Brocato y yo. Participaban, además, Juan Gelman, Guillermo Harispe, Hugo Acevedo, Ramón Plaza, Andrés Rivera, Horacio Casal, Estela Canto, Octavio Getino, Oscar Díaz, Carlos Gorriarena, Hugo Griffoi, Norberto Onofrio, Roberto Raschella, Roberto Aizemberg, Nemesio Juárez, Tito Cossa, Andrés Lizarraga, Susana Vallés, León Pomer, Javier Villafañe. El diagramador era Oscar Díaz. Una vez instalada se acercaron Pino Solanas, Alberto Fischerman, Norma Aleandro, Alberto Fernández de Rosa, Antonio Caparrós, Oscar Terán, Cristina Banegas, Beatriz Mátar, León Rozitchner y el gordo Cook" (Mangieri, 2004, 30)

$5 \mathrm{Al}$ respecto, como se sabe, hubo un intenso debate denominado como "No matarás" donde del Barco cuestionó las prácticas de las organizaciones armadas en los años 60 y 70. Cfr.: AA.VV. No matar. Sobre la responsabilidad, Córdoba, Ediciones del cíclope-Ediciones La intemperieEditorial de la Universidad Nacional de Córdoba, 2007, 461 pp.

6 Cfr. Mangieri, José Luis (2004), Es rigurosamente cierto, las páginas 27 a 29.

7 Para una diferenciación entre "lo político" y "la política", cfr. Bugnone, Ana (2014). La revista Hexágono '71 [1971-1975]. La Plata, Biblioteca Orbis Tertius y Centro de Arte Experimental Vigo. 
relaciones cuyas fluctuaciones están marcadas por la inestabilidad e intensidad de la vida política. ${ }^{8}$

Ahora bien, la figura del contrabandista, del que hace un uso plebeyo de la teoría, debe ser complejizada a la luz de las singularidades del catálogo que nos interesa explorar.

La veintena de títulos que conformaron la colección dirigida por del Barco constituye un tipo de práctica editorial donde la "lógica del dossier" en tanto articulación fragmentaria y selectiva de un conjunto de artículos tomados de diversas revistas puede leerse, en un segundo nivel de análisis, como una "política de la teoría". La colección "El hombre y su mundo" condensaría un espesor político dado no (solo) por el contenido de los textos o su relación con la coyuntura histórica en la que emergen, sino por la articulación singular entre prácticas editoriales donde leemos las huellas del roce con la vida política y social de las ideas, las marcas de apropiación de los textos publicados (en su totalidad traducciones) y las concepciones de "texto", "libro", "lenguaje" y "teoría" esbozadas en ellos. Si, como afirma Rancière en torno a una política de la literatura, esta lo es en tanto transforma el régimen de representación de una época dando lugar a la emergencia de subjetividades hasta entonces no contadas y poniendo de manifiesto una nocoincidencia entre la ideología que los textos portarían a través de sus autores y la politicidad de sus efectos, una política de la teoría puede definirse, para nuestro caso, como el modo por el cual la práctica editorial evidencia efectos políticos que desbordan -e incluso tensionan- las nociones teóricas que ponen a circular. El catálogo "El hombre y su mundo" performa lo que da a leer en el sentido en que su editor-del Barco- decide mostrarlo; es decir, los libros hacen en tanto objeto lo que dicen que hacen los textos: asediar la "ausencia de libro" y afirmarse en la fragmentariedad (Blanchot, 27), explorar la noción de escritura como borramiento de los límites de la noción de obra y de propiedad privada (Barthes y Kristeva, El

$8 \mathrm{O}$ bien, como ha señalado Diego García, una de las posibles y transitadas articulaciones entre política y edición ha sido "la renovación teórica entendida como 'arma de la revolución"” (García, 2014, 213). 
proceso de la escritura; Barthes, Sollers, Henric, Guyotat, Literatura, política y cambio; del Barco en Blanchot, "Leer Blanchot", todos libros por Ediciones Caldén). En ese sentido, la apropiación de la teoría traducida es inescindible de la dimensión material en que se ofrece a su lectura en el mercado editorial. Por último, como veremos, es en la yuxtaposición de textos traducidos y textos-comentario del propio del Barco, donde se conforma una poética editorial que permite leer la noción de "teoría" como forma de "experimentación con el tenor performativo del concepto" que pone en juego "un elemento subversivo de impredictibilidad" (Podlubne 88).

Para dar cuenta de cómo funciona esta política de la teoría, los siguientes dos apartados abordarán la historia de la editorial El Caldén a partir de la trayectoria de José Luis Mangieri y las relaciones de Oscar del Barco tanto con las pequeñas editoriales cordobesas del período como con la teoría francesa. Por último, en el cuarto apartado particularizamos la poética editorial de la colección con un análisis focalizado en La ausencia de libro. Nietzsche y la escritura fragmentaria, Maurice Blanchot.

\section{Ediciones Caldén y La Rosa Blindada: editoriales "hermanas"}

El origen de El Caldén es tan incierto y bordeado por relatos superpuestos como la mitología que puede rodear a los contrabandistas. A diferencia de la mítica Rosa Blindada, fundada también por Mangieri en 1962, El Caldén aparece de manera mucho más difusa tanto en los testimonios de quienes conocieron al editor como en las investigaciones sobre el mundo del libro en los años ' 60 y ' $70 .{ }^{9}$

9 En Editores y politicas editoriales en Argentina (1880-2010), Amelia Aguado hace una breve mención a La Rosa Blindada en el capítulo sobre "La consolidación del mercado interno (19561976)", como una de las editoriales de "orientación ideológica definida" (141), y repone un dato importante en torno a la ampliación del público lector propiciada por Eudeba, uno de cuyos efectos habría sido generar el marco donde se instalaron "las empresas más pequeñas de la década del sesenta y comienzos de los setenta" (Sarlo, 2001, 69 en Aguado, 2014,160). 
Alberto Díaz, editor de Siglo XXI, cuenta que 1969 es el año en que comienza "la gran actividad de La Rosa Blindada y de otros sellos editoriales creados por el mismo Mangieri”; se refiere entonces especialmente a Caldén y "una colección dirigida por del Barco, [que] publica a Artaud, a Derrida, a Lacan, etc.", y a continuación agrega:

en Ediciones del Siglo publica a Trotsky, a Garaudy, a Reich, a Dutschke. Pero la nave insignia seguía siendo La Rosa Blindada, que siempre estuvo acompañada por una constelación de editoriales, como estas u otras -todas creadas por Mangieri-, que expandían su influencia en el campo políticocultural de la época. (Díaz en Mangieri 121)

Este pasaje de Alberto Díaz da una pista para pensar a Ediciones El Caldén en una red de editoriales, y deja entrever un universo común, alrededor de la figura de Mangieri, entre todas ellas; asimismo, permite advertir que la colección de del Barco en El Caldén no fue simplemente una colección más, sino tal vez aquella por la que se destacó -en efecto, la editorial tuvo otra colección llamada "El narrador y su tiempo" 10 de la cual se conocen menos títulos y han sido recuperados solo en menor medida. ${ }^{11}$ Para aproximarnos a este sello es necesario entonces hacer un rodeo, acercarnos a él a través del derrotero de la misma Rosa Blindada como "nave insignia" que marca, respecto de la constelación de editoriales hermanas, continuidades en la estructura editorial, la financiación, la distribución, el diseño, la impresión y la procedencia de los textos.

Consignamos, en primer lugar, un listado de la Colección "El hombre y su mundo" según hemos podido reconstruir, ya que nos permite visualizar el lugar que

10 En el número 6 de la revista Los libros, de diciembre de 1969, se anuncian los siguientes libros de la colección, en el orden acá enumerados: Edgar Allan Poe, Charla con una momia y otros cuentos; Alberto Gurbanov, La pelotita (Cuentos de la alienación); Horacio N. Casal, Cuando se acabe la paciencia; Guy de Maupassant, Cuentos fantásticos; Nathaniel Hawthorne, Cuentos para ser contados dos veces; Blaise Cendrars, El alcantarillero de Londres; Saki, Antología fantástica; Gustave Flaubert, Memorias de un loco; A. von Arnim, Cuentos extraños.

11 Es notable que muchos de los libros de la Colección aparecen aún hoy como bibliografía de referencia en tesis o investigaciones actuales sobre la teoría. 
ocupó en ella la publicación de autores asociados a la teoría y la heterogeneidad en ciertas líneas de reflexión teórica.

1. Jean Paul Sartre. La trascendencia del ego. 1968

2. Bertolt Brecht, George Grosz, Erwin Piscator. Arte y sociedad. 1968

3. Lucien Goldman. Marxismo, dialéctica y estructuralismo. 1968

4. Karl Marx, Roger Garaudy. Textos sobre Hegel. El pensamiento hegeliano.

5. Althusser, Lacan, Foucault. Claves del estructuralismo. $1969^{12}$

6. Ludwing Feuerbach, Karl Max. La filosofía del futuro, Tesis sobre Feuerbach. 1969

7. Jean T. Desanti. Fenomenología y praxis. 1970

8. J. J. Rousseau, Jacques Derrida. El origen de las lenguas y La lingüística de Rousseau. 1970

9. Jean Hyppolite. Introducción a la filosofía de la historia de Hegel. 1970

10. Paul Klee. Teoría del arte moderno. 1971

11. Maurice Godelier; Lucien Seve. Lógica dialéctica y análisis de las estructuras. 1972

12. Maurice Blanchot. La ausencia del libro. Nietzsche y la escritura fragmentaria. 1973

13. Antonin Artaud. Textos revolucionarios: 1923 - 1946. 1972

14. Lacroix, Canguilhem, Hyppolite, Ambacher, Martin, Denis. Introducción a Bachelard. 1973

15. Jean Joseph Goux. Los equivalentes generales en el psicoanálisis. 1973

16. Roland Barthes, Jean Thibaudeau, Julia Kristeva. El proceso de la escritura. 1974

17. Antonin Artaud. Para terminar con el juicio de Dios y otros poemas.

18. Jacques Derrida, Julia Kristeva. El pensamiento de Antonin Artaud. 1975

19. Philippe Sollers, Pierre Guyotat, Jacques Henric. Literatura, política y cambio. 1976

20. Georges Bataille. Breve historia de erotismo. 1976

21. Antonin Artaud. Artaud el Momo y otros poemas. 1976

22. Claude Lévvi-Strauss. Elogio de la antropología. 1976

23. Jean Piaget. Autobiografia. El nacimiento de la inteligencia.

24. Edgar Morín, Norbert Wiener. Cibernética: necesidad e insuficiencia. 1976.

12 Este es un libro ejemplo respecto de cómo los nombres de los autores funcionaban, para la difusión, como marca de circulación, ya que el mismo estaba integrado por ensayos también de $\mathrm{P}$. Daix, Piaget, Barthes, Benveniste, Lacan, Wahl, compilado por Pierre Daix. 
Hay una doble relación, paradójica, entre lo que se propone con la conjunción "y" en el nombre de la colección -"el hombre" y "su mundo"-y los títulos publicados. Mientras la manera de nombrarse parece orientada hacia una perspectiva humanista que pretende abarcar cierta cosmovisión moderna de los debates sobre el "hombre", el tipo de diálogo y articulaciones conflictivas que se establecen entre los textos permiten advertir un giro sobre el propio nombre, donde es la cuestión del "hombre" en tanto primacía del individuo la que resulta cuestionada. Así la mayoría de los títulos publicados a partir de Teoría del arte moderno de Paul Klee reformulan las nociones de "ego", "sociedad" y "praxis" de los primeros libros de la colección, en un movimiento de revisión que podría pensarse en sintonía con la conferencia pronunciada por Jacques Derrida en 1968, titulada "Los fines del hombre". En diálogo con los principales presupuestos planteados allí, Oscar del Barco asimila el "humanismo" al "liberalismo" en la nota presentación a El proceso de la escritura (Barthes, Thibaudeau, Kristeva); Jacques Henric piensa las relaciones entre vanguardia teórica y vanguardia revolucionaria alrededor del "humanismo trascendental" como una fuerza revisionista que busca “obstruir, llenar, cubrir” toda grieta o resquicio (Henric).

Esta relación paradójica o suerte de articulación no-congruente que marcaría la conjunción " $y$ ” para los términos que busca conectar, puede pensarse en la misma dirección que propone la reunión, dentro del catálogo, de autores de la una teoría marxista, el estructuralismo y los autores de una "teoría de la escritura" o "vanguardia teórica" -como Philippe Sollers, Julia Kristeva, Jacques Derrida, Roland Barthes, Jacques Henric, Michele Foucault, Maurice Blanchot-, y aquellos vinculados con la noción de "ruptura" de las vanguardias, como Artaud, Bataille, Klee o Brecht. En uno de los ensayos introductorios de su colección, del Barco postula una figura que permite leer esa convergencia disonante de autores: se refiere a la "discontinuidad" como dispersión del "Sentido". La discontinuidad es el elemento a través del cual el editor piensa las relaciones entre literatura y política, o los límites a explorar donde lenguaje y política se encuentran; así habla de una 
experiencia de los límites / revolución [...] entendida no como presencia a sí de un Sentido que a partir del orden político sería "representada" por las distintas capas del todo social, sino como espacio donde la violencia, la destrucción, la deconstrucción, trabajan en una discontinuidad esencial: no hay un centro, un Sentido del acto revolucionario, sino la dispersión autónoma y a la vez no-autónoma del acto destructivo). (del Barco, "Leer Blanchot" 15)

El acto deconstructivo entonces, como dispersión que toca en parte a la revolución pero no solamente, es el que señala la discontinuidad de esas articulaciones suspendidas o no integradas, y el que dialoga con muchos de los textos publicados donde se habla de la différance y la écriture como "desgarraduras" (J. M. L., "Prólogo" a Literatura, política y cambio, 8$)^{13}$ en el "discurso económico logocéntrico" (8), como necesidad de disolver la propiedad tanto subjetiva como material (Sollers 34). Se trataba de una serie de articulaciones o un tipo de montaje en el catálogo donde una teoría de la escritura que se veía a sí misma como revolucionaria se proclamaba "ligada muy estrechamente a una revolución social" (Sollers 34).

Otro de los aspectos más relevantes de la colección se manifiesta en la búsqueda de una identidad visual que, paradójicamente, parece verse en constante movimiento o cambio [Ver imágenes]. Como vemos a continuación, la diagramación visual, al igual que el hecho de estar numerados, asemeja cada libro a la presentación periodizada de las revistas. Aspecto que a su vez coincide con cierta materialidad precaria de la encuadernación (carente de tapas con mayor

13 Las siglas J. M. L. aparecen como firma del "Prólogo" al libro Literatura, política y cambio que compila diversos textos del grupo Tel Quel. Podemos afirmar que se trata de un firmante "local" quien hace el prólogo - y no que este fuera una traducción más del volumen - porque alude a la importancia de pensar las rupturas en la noción de escritura y la "deconstrucción política" juntando a "Lenin, Mariátegui, Borges", "Macedonio", "Marx, Freud, Nietzsche, Sade, Mallarmé, Lautréamont, Derrida, Tel Quel" (J. M. L. 11). Suponemos que las siglas refieren a José Luis Mangieri y que por una errata en el orden se invirtieron las letras. No obstante, como se trata del único prólogo que no se encuentra firmado por Oscar del Barco, y el único con dichas siglas, así como no hay ninguno firmado por Mangieri, no tenemos otros elementos comparativos para afirmarnos certeramente en esta suposición. 
gramaje, y cocidos de buena terminación). El diseñador que más tapas realizó -no el único pero sí el principal- fue Oscar Díaz.
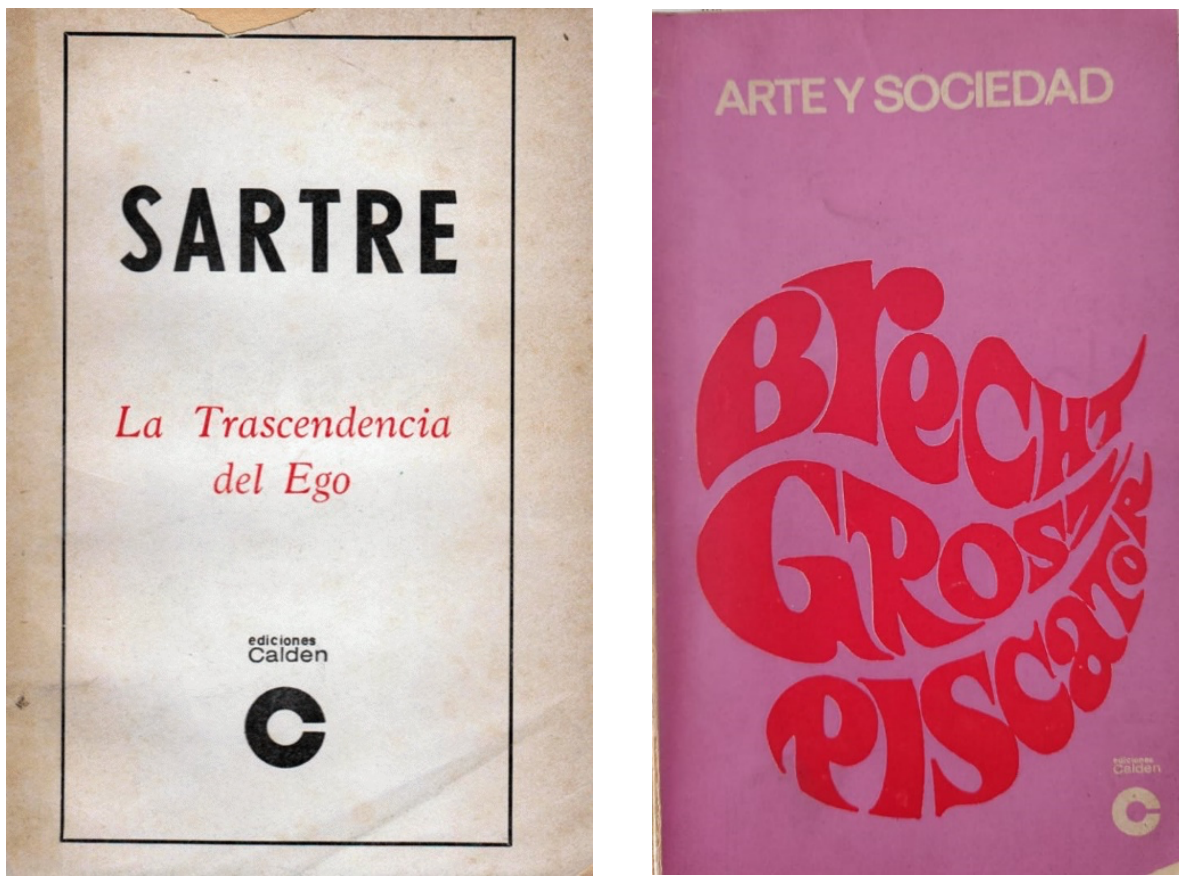

Imagen izquierda: Primer libro de la colección. La grilla y estilo del diseño continuará hasta el número 7 de "El hombre y su mundo", pero a la vez será interrumpido por el segundo libro [imagen derecha] donde se apela a una estética pop para presentar a los autores alemanes. 

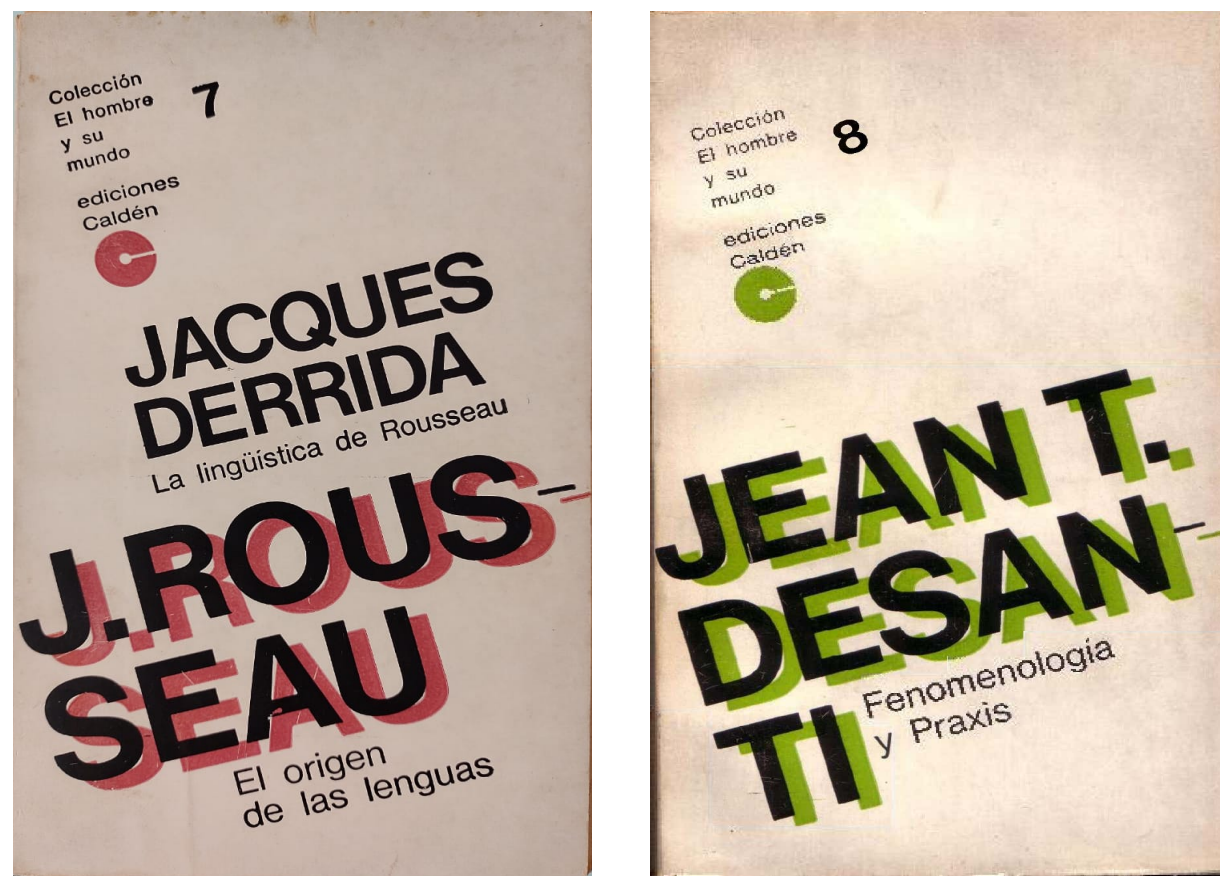

Estética y grilla adoptada hasta el libro número 16 de la colección.
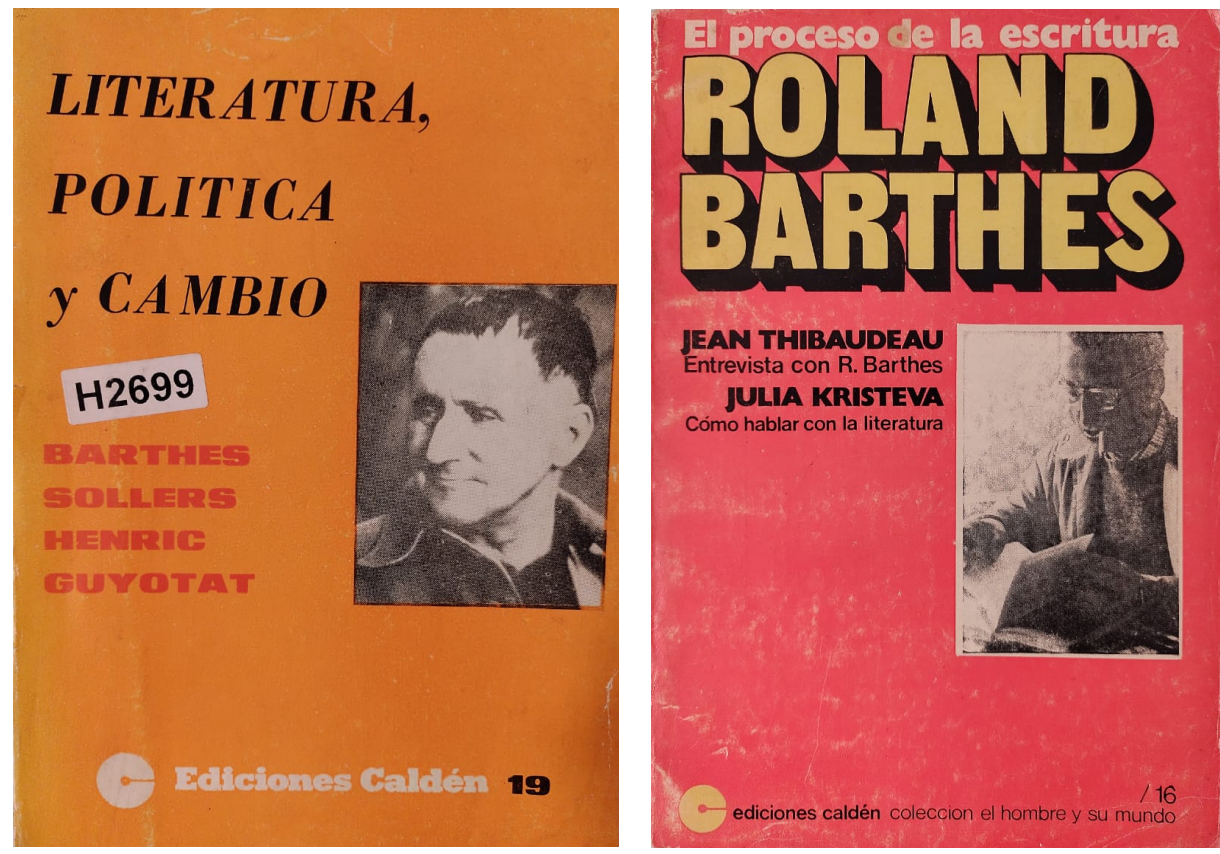

Diseño de los últimos libros publicados en la Colección "El hombre y su mundo" 
Oscar Díaz era integrante de La Rosa Blindada, ilustrador de Eudeba y CEAL, sin embargo, no se trataba solo de un colaborador cercano que luego habría sido convocado a diagramar algunas de las tapas de la Colección "El hombre y su mundo", sino que representaba, según el testimonio de Mangieri, una pieza central en su formación editorial:

A Eudeba entré gracias al Negro Díaz. Era la época de Boris Spivacow, que había sido uno de los fundadores del Movimiento Insurrexit, origen de la Federación Juvenil Comunista. Un buen tipo: muy neurótico, pero con una gran capacidad de trabajo. Se puede decir que él creó Eudeba, junto con Oscar Díaz, y Horacio Achával, y después el Centro Editor de América Latina. De Eudeba, más adelante, en la época de La Rosa Blindada, sacaría la idea de vender cuatro libros en un paquete, haciendo una preventa para financiarlos. Editamos cientos de títulos. (Mangieri 24)

Este relato, citado en múltiples oportunidades, especialmente en referencia a una tradición en el modo de hacer de las pequeñas editoriales autogestivas contemporáneas ${ }^{14}$ que buscan estrategias de financiación en mínima escala, tiene, más allá de su veracidad, la importancia de mostrar una trama de relaciones que no pueden sino apuntar a lo plebeyo y colectivo de la fundación de una editorial. Es por una cadena de afectos, amistades y aprendizajes, más que con un capital económico inicial, que se monta un catálogo y se producen "cientos de títulos". Oscar del Barco recuerda que nadie cobraba nada por lo que hacía en Ediciones Caldén, y continúa "no-trabajábamos sino que gozábamos haciendo lo que queríamos: SIN PROTOCOLOS, MÉTODOS, OBJETIVOS sí: GOZABAMOS”. 15

14 Cfr.: Vanoli, Hernán: "La 'tradición independiente' en la edición literaria argentinasexual y la inclusión en el consumo mediante la estrategia "gay friendly". IX Jornadas de Sociología. Facultad de Ciencias Sociales, Universidad de Buenos Aires, 2011. Disponible en: https://www.aacademica.org/000-034/12 (visitado el 22/04/2021).

15 Entrevista con la autora. 
También con respecto a la impresión y la financiación de la editorial, podemos observar una red de compañeros o amigos. Mangieri cuenta que, en un comienzo, los libros los hacía Bocatto, "los componía clandestinamente en una imprenta de Lanús, donde teníamos un capataz amigo. Íbamos de noche y, mientras Brocatto componía, yo le cebaba mate" (30). Poco después, Mangieri pudo tener una imprenta propia, los Talleres Gráficos Schmidl - por Ulrico Schmidl, el "cartógrafo de Pedro de Mendoza" (30). Si observamos los colofones veremos que esta imprenta aparece como lugar de realización de los libros, pero de manera intermitente y no siempre con la misma dirección. Por ejemplo, Arte y sociedad, de Bretch, Grosz y Piscator, el segundo libro de la colección, dice en el colofón: "Este Libro se Terminó de Imprimir en los Talleres de IMPRESIONES SCHMIDEL, Schmidel 5657, Buenos Aires, El Día 23 de Agosto de 1968”; el libro de Rousseau y Derrida, en cambio, se imprime en Editorial Quetzal en Callao 335, mismo taller de Teoría del arte moderno de Paul Klee, pero con otra dirección: Marcos Sastre 330; el libro de Maurice Blanchot aparece con otro pie de imprenta, Edigraf, Delgado 834, mientras que El proceso de la escritura y Literatura, política y cambio -editados entre 1974 y 1976- vuelven a ser impresos en Talleres Schmidl, con una nueva dirección, Cosquín 1172. Estas variaciones hablan, en todo caso, tal vez menos de una serie de mascaradas que de la itinerancia de un proyecto cuyo funcionamiento mostraba los vaivenes de una estructura financiera y organizativa poco sólida.

Hay un dato más en el relato que Mangieri hace sobre la experiencia de su taller, y es el modo en que establece directamente un vínculo con el mundo de las librerías:

[...] entre 1968 y 1976, la imprenta y la editorial siguieron funcionando bien, pero entretanto, la economía se iba descalabrando. [...] hubo un momento en que la cosa se empezó a poner muy difícil con los libreros, que empezaban a arrugar. No se lo reprocho: los tipos viven de vender 
libros, no de que se los secuestren o quemen, sin hablar de la integridad personal. (26)

Esta mención a los libreros tiene, cuando leemos el testimonio del editor Alberto Díaz una relevancia particular para pensar la financiación de los proyectos editoriales de Mangieri, ya que habría sido Hernández, el mítico librero de la calle Corrientes, el que sostuvo esa constelación de editoriales y los cientos de libros que se publicaban en La Rosa Blindada, Ediciones del Siglo y Ediciones Caldén, comprando 3000 ejemplares en firme de cada título. ${ }^{16}$ Hernández se exiliaría en Uruguay en 1976, y eso puede explicar por qué algunos títulos de El Caldén son publicados del otro lado del Río a partir de esa fecha, con otros diseños de portada [Ver imágenes].

16 Transcribo el relato completo porque repone el encanto del murmullo y la leyenda en que se ha narrado el itinerario de la editorial: Ante la fuerte presencia de los libros publicados por José Luis, la Galaxia Gutemberg y el mundillo de la izquierda empezó a preguntarse quién financiaba esta formidable expansión editorial. La respuesta de esta incógnita llegó de la mano de los libros que publicaba: El libro rojo, Acerca de la práctica, A propósito de la contradicción, Escritos Militares, Obras escogidas, La nueva democracia. Todos libros escritos por Mao Tse Tung, lo cual lleva a develar el misterio. Los chinos financiaban a José Luis. Fin de la incógnita. Pero si la realidad es dura, la verdad lo es mucho más. Un curioso personaje, Hernández, así a secas, va a develar el misterio. ¿Quién era Hernández? Hernández era un extraordinario librero que instala su primera librería por allá por los cincuenta en la calle Corrientes, casi esquina Uruguay, donde todavía sigue funcionando. Cuando este rumor llega a oídos de Hernández, este reacciona indignado: qué lo van a financiar los chinos, a Mangieri lo financio yo. Y así era, Hernández compraba mínimo 3000 ejemplares de cada uno de los títulos que publicaba La Rosa Blindada o las otras editoriales hermanas. Hernández era un gran librero y una excelente persona, no un Mecenas. Los libros de la Rosa tenían un público lector amplio y fiel. Sus libros viajaban por toda América, en donde encontraban al mismo lector. (Díaz en Mangieri, 2004, 121) 

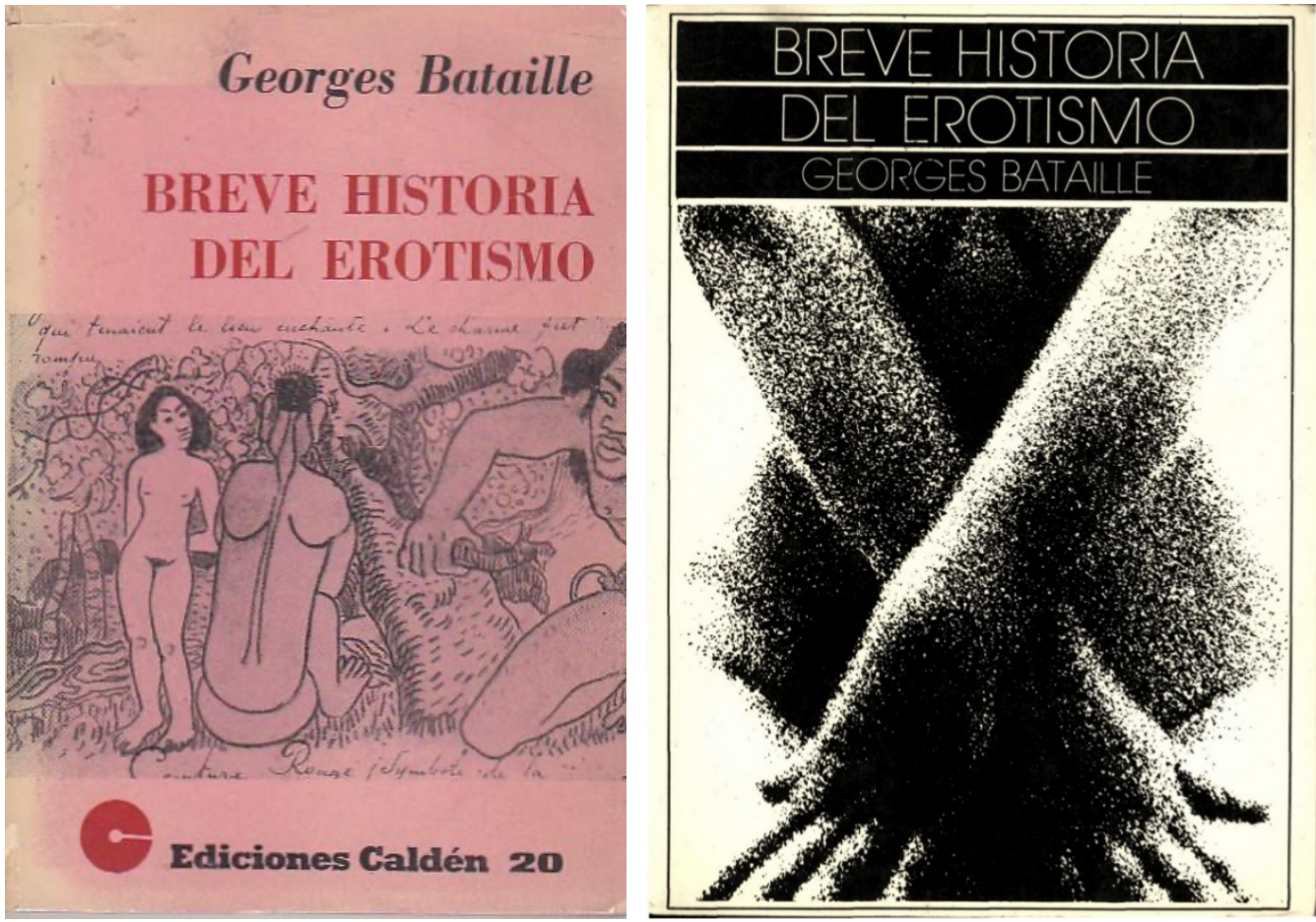

A la izquierda: edición de Breve historia del erotismo de 1976 impreso en Buenos Aires. A la derecha: edición que en su colofón recupera la fecha de 1976 pero también indica "Montevideo 1982". Lo mismo ocurre con las ediciones de Paul Klee.
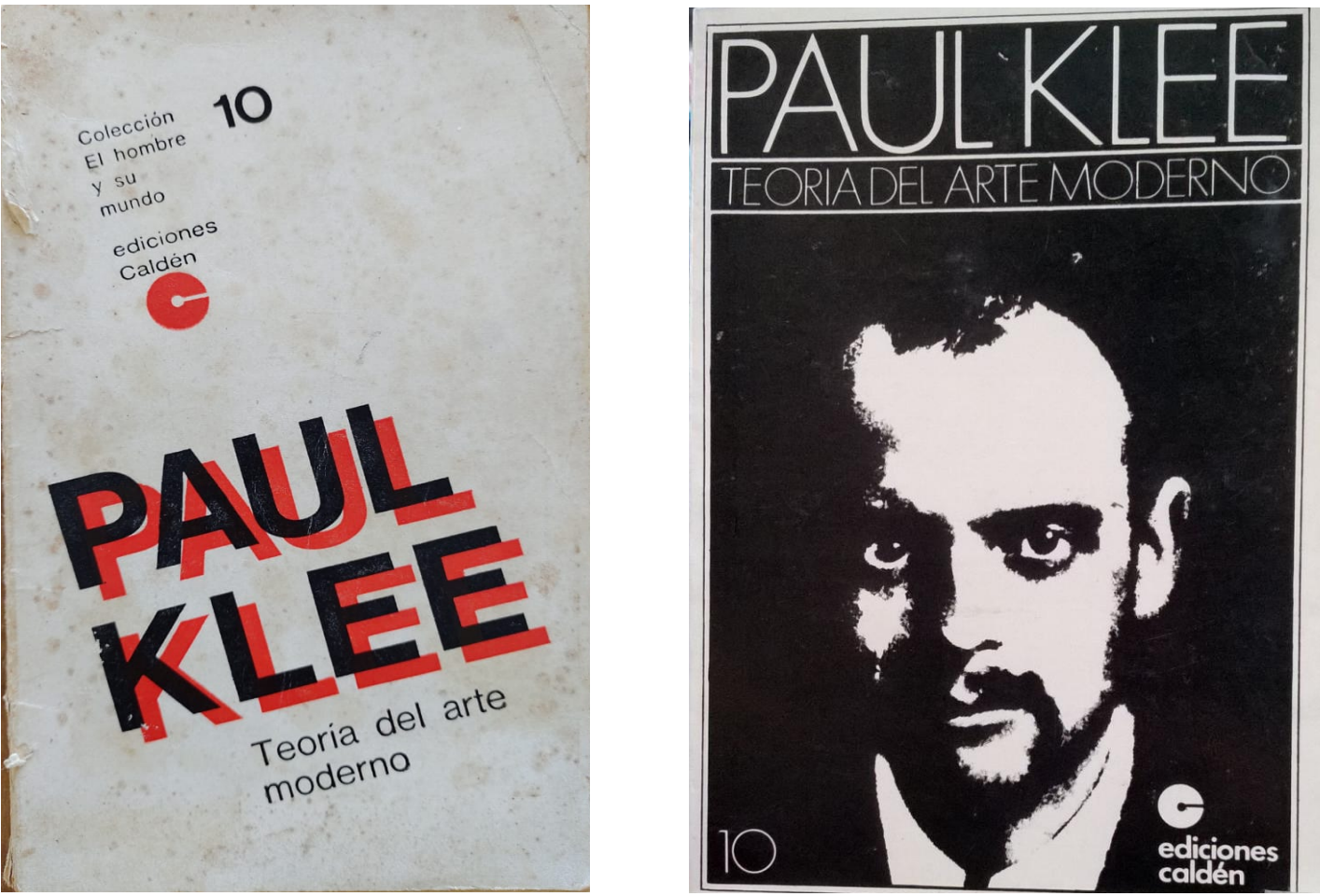
Hasta acá, los testimonios de Díaz y Mangieri, así como algunos datos recabados de la información que nos ofrecen los paratextos de los libros, explican en parte un proyecto en los márgenes de la legalidad editorial. Cuando Del Barco dice “éramos LADRONES, ¡no teníamos ni pagábamos ni un peso!”, está diciendo también no le pedíamos permiso a nadie. El universo de la cesión de derechos, los contratos con autores y formalidades de la edición parece excluido de la vida editorial de Ediciones Caldén. Sin embargo, esto no explica por qué se trataría, a su vez, de una experiencia contrabandista y plebeya de la teoría, y en qué medida esto tendría un efecto sobre la conformación de un espacio de la teoría. Para ello es necesario reparar más particularmente en las singularidades de algunos libros de la Colección "El hombre y su mundo" y el modo en que el contrabando no se refiere solo a una forma de la falta de pago, sino también a la construcción de un catálogo hecho con piezas extraídas y recolocadas en un universo de sentido que se configura como nuevo en la colección argentina.

\section{Oscar del Barco editor: la colección "El hombre y su mundo" en las redes editoriales cordobesas}

Ignacio Barbeito ha postulado que es un error creer que Pasado y Presente ocupó todo lo que tenía que ver con las relaciones entre cultura, política y edición en Córdoba, así como también es un error atribuirle a la mítica revista -y su proyecto editorial- el acontecimiento de autores como el Marqués de Sade, Stéphane Mallarmé, Antonin Artaud y Georges Bataille. Con esta afirmación, Barbeito recorta a Oscar Del Barco de la lógica del proyecto y repone su singularidad en él, ya que la idea gramsciana de cultura en Pasado y Presente signada por el sentido de la organización y la disciplina del propio "yo interior"habría estado en tensión con un registro teórico que se empeñaba en mostrar la ausencia de sujeto (144). Eso que Barbeito llama "parnaso francés" (143) cuando se refiere a Sade, Mallarmé, Artaud y Bataille, es parte de la biblioteca que la 
"vanguardia teórica" de los años 60 recupera del agua que corrió bajo el puente de las vanguardias históricas a fines del siglo XIX y principios del XX. En ese sentido, nos interesa analizar dos experiencias editoriales breves y minúsculas donde del Barco estuvo involucrado en ellas como editor o traductor, y nos permiten visualizar el funcionamiento de construcción de una poética editorial "contrabandista" que se entrama con los vínculos entre diversas editoriales.

Entre 1965 y 1970, Bernardo Nagelkop llevó adelante un proyecto editorial con su nombre, y tuvo también una suerte de editorial fantasma, Garfio Ediciones, donde publicó Sade, filósofo de la perversión en 1968, compilación de artículos de Klossowsky, Barthes, Sollers (entre otros), traducidos por Oscar del Barco con el seudónimo habitual de Alberto Drazul. Además de exhibir el carácter pirata desde el título, Garfio ediciones se anticiparía, en la traducción de autores como Philippe Sollers -incluido en el volumen sobre Sade- a los españoles de Pre-Textos ${ }^{17}$ y por poco tiempo a la edición de Paidós -que publicó el mismo libro con el nombre $E l$ pensamiento de Sade. Esta última editorial sí contaba con los derechos para la edición en Argentina y haría la denuncia correspondiente contra Nagelkop. Según Barbeito, "[e]ste y los otros libros de Sade editados por Nagelkop obedecían, casi con certeza, al consejo de del Barco"; ${ }^{18}$ en la ausencia de un mensaje-Sade -al que del Barco proponía como "enigma”: "¿su obra es una apología del odio y el crimen?, ¿qué universo nos propone Sade?”, se preguntaba en el primer número de Los libros - se emplazan las escrituras y estéticas rupturistas que la teoría tomaría para sí: "Bataille y Artaud fueron dos tipos muy importantes para nosotros en esa

17 Sello con el que siguieron adelante cuando Nagelkop supo que Paidós había comprado los derechos para hacer El pensamiento de Sade con ensayos de Klossowsky, Barthes, Sollers, et. Al, en la colección "Letras mayúsculas" dirigida por David Viñas y que aparecería en 1969. La maniobra fue descubierta por Paidós y responsabilizó a Bernardo Nagelkop. Las traducciones las había hecho Del Barco. En efecto, los trabajos reunidos en Sade, filósofo de la perversión, habían sido originalmente publicados en el número 27 de Tel quel, aparecido en Francia apenas un año antes" (Barbeito 145)

18 No se habría tratado entonces, según Barbeito, de la "concepción embrionaria del papel de la cultura en la transformación de la política" (145) que Pasado y Presente consagraría posteriormente con la serie de los Cuadernos; "era más bien una manera de contribuir a desencajar la palabra de la tendencia predominante a subordinarla a la mera satisfacción de requerimientos de utilidad". Y concluye: "[e]sta tendencia no tenía ni tendría ningún ascendente sobre Pasado y Presente" (145). 
época errática, desbocada, y bastante digamos esquizo (porque a todo esto nuestro telón de fondo era cuba, la guerrilla, etc. / sin esta "visión" creo que el accionar de p. y p. es ininteligible". ${ }^{19}$ Hay que notar, en la trama de estas ediciones, que el afán por apropiarse una biblioteca de esa "modernidad" no está escindido de un afán por hacerla circular, incluso si se carecía de los permisos adecuados.

En este relato de ediciones piratas, de una forma de leer y editar “desbocada", podemos localizar un vínculo vertiginoso y voraz con la teoría, donde lo que se contrabandea, además de los derechos, era la posibilidad de montar -en el sentido más estricto de montaje- un universo de conjunto. No importa que Paidós o Pre-textos o Taurus o Sur incluso, hubieran publicado a Bataille, a este o el otro lado del Atlántico, en español, lo que importa es cerca de qué otros autores puede ser leído. Este episodio del contrabando en su sentido más literal, el "robo", adopta otros matices si se analiza la trama de relaciones editoriales donde del Barco se encontraba inserto, y en cuyas fibras iría configurando -aunque sin planificación, según su propio relato- los contornos de una política de la teoría hecha a partir el contrabando en tanto movimiento fragmentario de las piezas arrancadas de su contexto de publicación original y recolocadas en un nuevo montaje.

Entre 1968 y 1971 la actividad editorial de Oscar Del Barco involucró tanto su tránsito por Ediciones Caldén como por Ediciones Signos y Siglo XXI. El catálogo de Ediciones Signos de 1970 anunciaba a Del Barco como director de la colección "Pasado y Presente Literatura", en una clara referencia del escritor con la revista de la cual formaba parte. Sin embargo, la colección completa no saldría en Signos, ya que en 1971 sus integrantes -Juan Carlos Garavaglia, Enrique Tandeter, José Aricó y Héctor Schmucler- deciden disolver la editorial y fusionarse con Siglo XXI, donde se publicarían varios de los títulos anunciados. ${ }^{20}$ No obstante ese giro

\section{Entrevista con la autora.}

20 En el folleto de Ediciones Signos se anunciaban, para la colección que dirigiría Del Barco Pasado y Presente Literatura-, los siguientes títulos: Georges Bataille, Las lágrimas de Eros; Stephane Mallarme, Igitur o la locura de Elbehnon; Williams Burroughs, Cartas del Yage; Alfred Jarry, El amor absoluto - El otro Alceste. La selección da cuenta de un tipo de vanguardia literaria y contracultural: Mallarme y Jarry -autores del siglo XIX apropiados por las vanguardias de comienzos del XX como quienes abrieron la inquietud por el orden de la lengua-, Burroughs $\mathrm{y}$ 
del proyecto de Signos Editorial, uno de los libros que sí saldría publicado por el sello de Garavaglia, Tandeter y Schmucler es Las lágrimas de Eros de Georges Bataille.
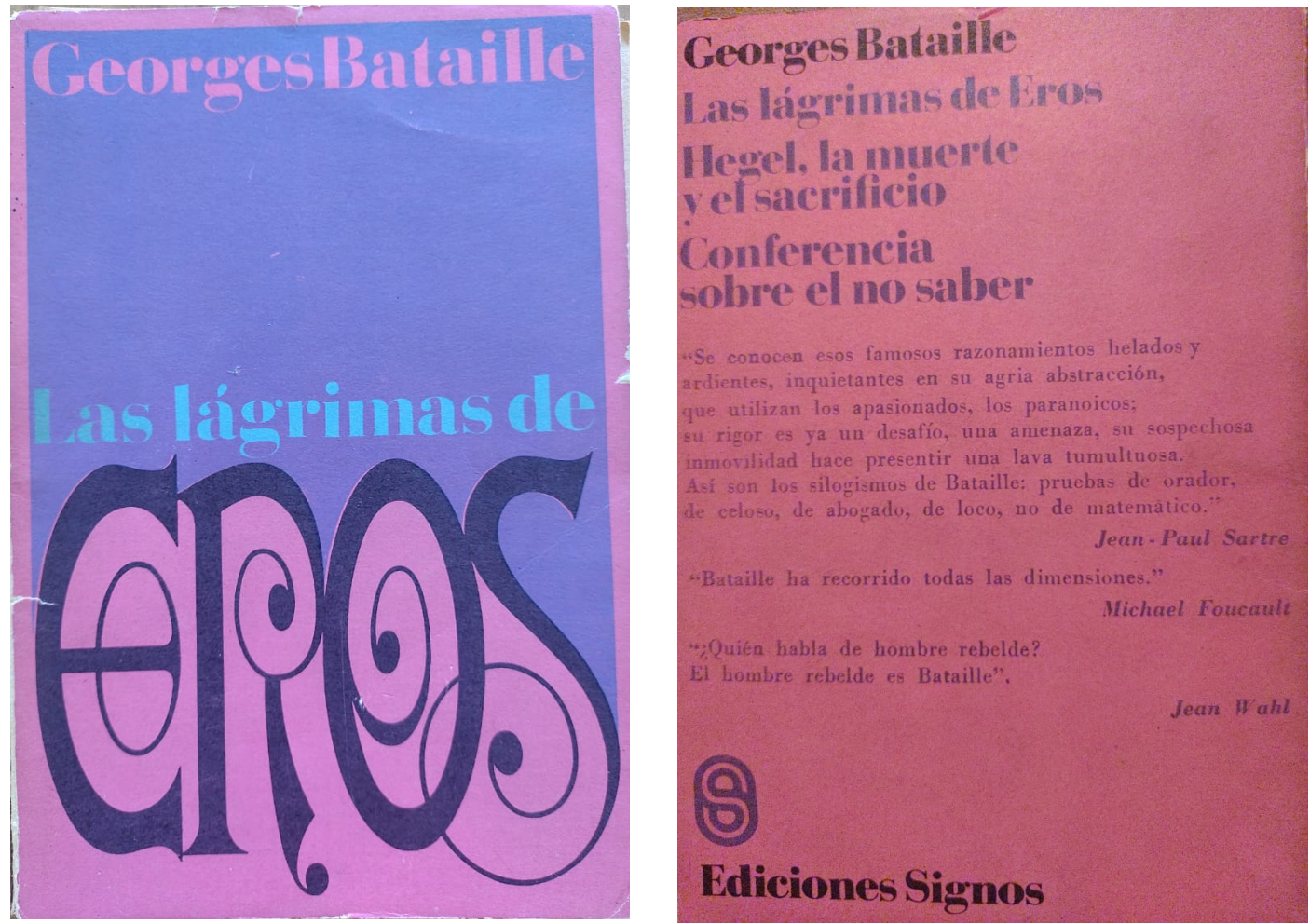

El derrotero de este libro permite un doble movimiento: por un lado, como veremos a continuación, muestra cómo la forma del "contrabando" opera en una serie de montajes y reorganización de los textos; y al mismo tiempo nos conecta con dos de los títulos de la colección "El hombre y su mundo", Breve historia del erotismo, de Georges Bataille (1976), y con La lingüistica de Rousseau. El origen de las lenguas de Jacques Derrida y Jean-Jacques Rousseau (1970), ya que en ambos observamos las conexiones y trasvasamientos entre proyectos que quedan truncos y se recuperan en otros espacios. En ese sentido, el contrabando no sería

Bataille, asociados a una ética de la transgresión. Para un análisis pormenorizado de la editorial Signos y las trayectorias de sus editores y colecciones, véase García, Diego, "Signos. Notas sobre un momento editorial". 
solo un modo de robo o "importación” de la teoría, sino un tipo de circulación entre editoriales locales cuyas estructuras parecen tan precarias como los textos que ponen en circulación.

Según Diego García, Las lágrimas de Eros es anticipado en el primer número de Los libros (1969) como una publicación de Pasado y Presente; no obstante, aparece luego en el folleto de Signos como el primer título de la colección PyP Literatura; el catálogo de Siglo XXI del año 2005 lo indica, a su vez, como una publicación de Signos de 1968 (es decir que cuando Los Libros habría anunciado su pronta aparición en el '69, ya habría estado circulando), año que coincide con el que leemos en colofón. Para contribuir a los solapamientos, Las lágrimas de Eros se compone de tres ensayos, de los cuales solo uno corresponde a la traducción de una parte de Les larmes d'Éros (publicado en Francia en 1961 por Minuit) pero en las referencias no se remite al libro, sino al número 5 de la revista Tel Quel ${ }^{21}$. Les larmes d'Éros será traducido de forma completa, en cambio, con el título Breve historia del erotismo en El Caldén ediciones en 1976 (algunos ejemplares figuran con fechas posteriores de impresión y son localizados en Montevideo), mientras que la editorial Sur había publicado en 1961 El erotismo [1957 en la edición francesa].

Ahora bien, es importante reparar en que Las lágrimas de Eros efectivamente se publicó en Signos. El único ejemplar que pudimos consultar tiene arrancadas las primeras páginas, donde encontraríamos el texto de "Advertencia" a la edición, y más datos sobre la fecha y lugar de publicación. No obstante, podemos acceder al índice, al primer ensayo de manera incompleta, y los dos siguientes de forma completa. El título "Las lágrimas de Eros" funciona como una suerte de

21 Otro de los libros donde eso sucede con notable evidencia es en Literatura, política y cambio. Se trata de un libro que reúne en ensayos de Barthes, Sollers, Henric y Guyotat, se traduce "El reflejo de la reducción" de Philippe Sollers y se indica que el mismo fue extraído de La Quinzaine littéraire, enero 1968. No obstante, el mimo artículo integraba un volumen fundacional del grupo Tel Quel, denominado Teoría de conjunto (1968) -manifiesto donde participaron Phillipe Sollers, Roland Barthes, Julia Kristeva, Jacques Derrida, Michel Foucault entre otros, y que sería publicado en 1971 por Seix Barral. Es decir que no se trata solo de sortear los derechos a una edición formal como la que ofrecer Seix Barral, sino ante todo, reponer y poner en escena, el contexto de publicación periódica de donde provenía el texto, antes que la antología que lo incluía y había trascendido como manifiesto del grupo. 
prosopon editorial, una máscara que habla. Mientras Les larmes d'Eros se trató de uno de los proyectos que Bataille intentaba terminar-como los tomos de La parte maldita - mientras la tuberculosis avanzaba sobre su cuerpo, dedicado a pensar una historia del arte moderno desde la noción de erotismo ${ }^{22}$, Las lágrimas de Eros tiene sin dudas otra dirección. La compilación de tres artículos aparecidos en Tel Quel y Deucalion - «Les larmes d'Eros », Tel Quel, n. 5, 1961, traductor Alberto Drazul; «Hegel, la mort, et le sacrifice », Deucalion, octubre de 1955, traductor Emilio Terzaga; «Conferences sur le Non-savoir », Tel Quel, n. 10, 1962, traductor: Alfredo Paiva- pone el énfasis en otras zonas del pensamiento de Bataille, aquella que articula los ensayos sobre el "no saber" y las relaciones entre el límite del lenguaje y la rebelión. Es decir que con el nombre de una transgresión erótica se daba lugar a un problema de orden más amplio, la transgresión del sentido como abandono del dominio "estable de lo conocido" (Bataille, Las lágrimas de Eros 63) donde la "seguridad es subvertida" (65) en lo que denomina como "experiencia del instante" (77) y "no saber". Así, afirma Bataille, la rebeldía se convierte en "rebeldía [filosófica] contra todo el mundo del trabajo y contra todo el mundo de los presupuestos" (76). Esta operación, de tomar el título de un libro para publicar un conjunto de artículos cuya procedencia citada son dos revistas contemporáneas, invita a seguir pensando la poética editorial de del Barco, como una edición de la fragmentariedad, donde lo que se contrabandea además son determinados sentidos, tal vez menos audibles para época, que van como polizones en el más rimbombante sonido de "Eros".

Es en ese sentido que la lógica de armar libros a partir de publicaciones en revistas no debería reducirse solo una "estrategia" o a lo que del Barco llama "falta de protocolos", sino que tiene un efecto performático en el mundo del libro en tanto organiza una puesta en circulación de las escrituras y ofrece una lógica de conjunto diferente a la de la Obra (es decir, aquello hecho, producido, cerrado) y aún mucho 
más alejado de la idea de las Obras Completas. En el libro de Rousseau y Derrida, publicado también por Caldén Ediciones en 1970, se "advierte":

El artículo de Jacques Derrida fue traducido de la Revue internationale de Philosophie, nº2, 1967, Ch. Porset, en la edición citada, señala la importancia de la obra capital de Jacques Derrida (De la grammatologie) para la lectura del Ensayo. Próxima a aparecer dicha obra en ediciones Signos, el presente artículo es una estricta introducción al Ensayo de Rousseau y también a De la grammatologie. ${ }^{23}$

De la gramatología, el libro anunciado, no se publica finalmente por Signos, sino por Siglo XXI, y se trata, esta vez sí, de la traducción de una obra, por otra parte, extensa. Podríamos aventurar que esta empresa responde a cuestiones económicas, ya que probablemente Orfila Reynal les pagara a del Barco y Funes responsables de la traducción- lo que no le pagaba Mangieri por traducir artículos, compilarlos, editarlos y firmarlos con el seudónimo de Alberto Drazul. No obstante, parece imponerse, en parte, la fuerza performativa del catálogo, como si Siglo XXI fuera el tipo de editorial que publica las Obras, mientras la colección "El hombre y su mundo" y las ediciones Caldén hacen una labor fanzinesca, folleteril, revistera de la teoría literaria. Y es esto último lo que posibilita esa edición "desbocada", voraz, donde en poco tiempo y en forma breve, pueden convivir Sartre con Blanchot, Marx con Artaud y Bataille, Goldmann con Derrida. Esa voracidad, desboque o vértigo no puede pensarse sin cierta acefalidad -como ha propuesto Raúl Antelo para pensar claves de la modernidad latinoamericana- de la que del Barco es sin dudas deudor en tanto que lector de Bataille. Un pensamiento acéfalo, sin la unidad de la autoridad como rectora, no es ecléctico sino heterológico, ${ }^{24}$ insumiso a ser circunscripto a un único sentido.

23 Nota editorial a Derrida, J.; Rousseau, J. La lingüistica de Rousseau. El origen de las lenguas. Buenos Aires: Ediciones Caldén, 1970.

24 Con la noción de heterología, Bataille refiere a lo heterogéneo como aquello que se ubica y trabaja antes del código; es decir, cuerpos extraños que no son asimilados en la identidad. 
En una relación muy estrecha entre lecturas y el universo de las materialidades por donde circulaban, esa acefalidad adoptaba, según del Barco, cierto carácter de mezcla que insiste en un modo revisteril de pensar y hacer libros en tanto modo de hacer teoría:

todo mezclado: los intelectuales comunistas italianos y franceses, las revistas Aut-Aut y Tel-Quel, metafísica y moral, etc., el ejército guerrillero del pueblo y luego montoneros, etc. - ningún compartimento estanco, música, pintura, filosofía, lingüística, poesía, etc. etc. y claro, la política era como la propia vida, el mayo francés, el Cordobazo, la insurrección, la revolución, viajes, etc. un "fárrago", diría Kant, y nosotros navegando en esos torrentes.

Sin embargo, esa mezcla no ignoraba el rigor de lo que llamaban "pensamiento teórico" (el límite del desmalezamiento de las mistificaciones, como lo nombraría Sollers en una entrevista y Mangieri en una nota editorial), aunque esta primera muchas veces lo desbordara.

\section{Navegando en torrentes: una política de la teoría}

Literatura, política y cambio, el libro número 19 de la colección que compila artículos, entrevistas y manifiestos de Philippe Sollers, Pierre Guyotat, Jacques Henric y Roland Barthes, nos ofrece una clave certera de lo que mencionamos al inicio del apartado anterior como la influencia de Tel Quel en la selección de textos que integran el catálogo dirigido por del Barco. Esta influencia explica, en parte, lo que el editor nombraba en términos de mezcla, ya que son numerosas las insistencias de Sollers, miembro emblemático de la revista francesa, por pensar una noción leninista de la cultura desde la diseminación derrideana por ejemplo. Esa mezcla adopta la forma de un dilema, que es el que para del Barco debe permanecer acefálico, es decir no subsumir ninguno de sus términos a un 
sentido que lo reduzca. ${ }^{25}$ Según leemos en el "Prólogo" -aparentemente firmado por José Luis Mangieri-, el dilema al que parece responder el libro es el de "literatura o revolución", y lo asume con la siguiente consigna telqueliana: "No se puede hacer una revolución económica y social sin hacer, al mismo tiempo y en otro plano, una revolución simbólica" (J. M. L., 11). ${ }^{26}$ Según el prólogo a los ensayos de Literatura, política y cambio - una suerte de programa en cinco puntos

25 En septiembre de 1971, del Barco había discutido fuertemente la posición de la revista Los libros frente al "Caso Padilla". En nombre de una "correcta lectura teórica" - y no en nombre de la libertad- afirmaba que la revolución entendida estrictamente en términos de política del partido era una visión incompleta y reductora del todo social heterogéneo que comprometía la transformación radical de las cosas (del Barco, "Polémica" 32): “[...] la idea de la sociedad entendida como un todo homogéneo es una idea hegeliana como lo ha demostrado Althusser [...], la sociedad es un todo integrado por distintos niveles, productos de distintas prácticas, que poseen legalidades y temporalidades distintas, y cuya dominancia es histórica y no substancial. [...] la revolución política no es LA revolución. En todo caso, si se pudiera hablar de LA revolución, esta sería la suma de las revoluciones política, económica, ética, teórica ... [...] Si el dirigente político no es el depositario del SENTIDO de la revolución (una especie de gran sacerdote que representaría a la Revolución, como si la revolución fuese una Idea o un Dios), ¿de acuerdo a qué facultad sobrehumana podría indicarle a un orfebre cómo se talla una piedra, a un pintor cómo se pinta, a un poeta cómo deben ser sus poesías? ¿por qué todo el mundo se da cuenta de que es absurdo querer enseñarle a un relojero a hacer relojes y no se da cuenta que es tanto o más absurdo querer decirle a un novelista cómo se debe escribir y de qué deben tratar sus novelas?" (del Barco, "Polémica", 32). Es curioso notar al respecto que en la nota editorial al libro El proceso de la escritura - dedicado a Roland Barthes en 1974 - del Barco emplea el mismo argumento y utiliza la expresión "revolución policéfala", como si para el momento de enunciación fuera demasiado arriesgado tan solo esbozar la ausencia de una cabeza: "Los trabajos de R. Barthes son "críticos" en este sentido; en ellos la literatura, el arte, la ciencia, son corroídos desde dentro, son desplazados de sus lugares. Y una sociedad donde los lugares se desplazan está sometida al proceso revolucionario que trabaja en el todo social, no solo en lo "político" (lo que sería aceptar la división del trabajo burguesa, que dice: la política se hace aquí, la hacen los políticos, ya sean de derecha o de izquierda) sino en la trama de infinidad de instancias, de movimientos, de lugares, en el desplazamiento de los deseos y las luchas, de manera tal que es posible hablar de la revolución como acto policéfalo, como metástasis incontrolada e incontrolable, descentrada, de la corrosión, corrupción, transformación que no supera sino que destruye para que nazca lo otro." (del Barco, "Presentación" 7)

26 Como se mencionó antes, se trata de un número singular en la colección. Curiosamente lleva en la tapa un retrato de Bertolt Brecht aunque ninguno de los textos está firmado por el escritor alemán ni se refieren a él. Por último, se trata de una de las compilaciones más heterogéneas en los textos reunidos y también más desprolija en cuanto a la mención de las referencias; en efecto, en las primeras entrevistas -a Philippe Sollers y a Roland Barthes- no figura ninguna información acerca de quién es el/la entrevistador/a, cuál fue el marco de su realización y de dónde fueron extraídas. 
-, dicho dilema debía resolverse no solo en lo simbólico sino en la noción de "texto" en tanto ella encarnaba además la "ausencia de sujeto": 27

Dijimos Marx, Freud, Nietzsche, Sade, Mallarme, Lautréamont, Derrida, Tel quel; podemos decir Lenin, Mariátegui, Borges. Con todo, ya no sujetos - psicologías, individuales, dueños de un sentido- ya no autores, que valen de acuerdo con su capital significativo: ahora fragmentos textuales, que se implican y relacionan con otros en un espacio. Múltiple discurso político revolucionario: materializa la deconstrucción práctica de todos los códigos ligados -y constituyentes- del logocentrismo. (J.M.L. 11)

La articulación de los nombres europeos con la línea Borges-Mariátegui (en sí misma singular) da cuenta de que la idea de "influencia" -en relación con $\mathrm{Tel}$ Quel- resulta si no insuficiente al menos necesaria de interrogación para pensar la otra dimensión de eso que del Barco llama "fárrago": la sensación de estar navegando en torrentes o bien, un vínculo voraz y desbocado con la teoría que en Argentina adoptaba constantemente entre sus horizontes de enunciación las formas más radicalizadas de la acción política. En todo caso, se trataría de observar lo que sucede en la apropiación de ese programa telqueliano -con sus sustracciones y excedencias- en relación con el tipo de dispositivo que supone un catálogo editorial, y los efectos propios que tiene el vínculo "literatura - revolución". Como trataremos de mostrar, la edición empuja, en sus efectos, sentidos sobre la teoría que son imprevisibles sin el encuentro con el material tal y como Ediciones Caldén lo propone. Así, la conformación misma del catálogo que es "El hombre y su mundo" excede la trasmutación del programa Tel Quel, porque cada uno de los

27 Incluso podría pensarse que La trascendencia del Ego es un contrapunto vinculante con las búsquedas por cuestionar las nociones de "yo" -propietario de la subjetividad-, de individuo, sujeto hablante. 
libros y el conjunto de ellos ejercen una fuerza performativa sobre aquello que dicen.

Tomemos como caso el número 12 de la colección y una serie de textos que lo rodean. En La ausencia del libro. Nietzsche y la escritura fragmentaria de Maurice Blanchot, la noción "ausencia de libro" 28 remite al cuestionamiento de la idea de origen y del libro como presencia, suma de Saber, origen de la cultura, consolidación de la Obra. Mientras el libro desempeñaría "un papel dialéctico" (Blanchot, 28) porque "envuelve y desenvuelve el tiempo" (29), en tanto presupone un comienzo y un fin, un pasado y un porvenir, la "ausencia de libro" anula la continuidad de la presencia. Sin embargo, "ausencia de libro" no es "negación del libro" ni siquiera su "exterior", es "la referencia a un afuera que no lo concierne" (34); se trata de "la astucia por medio de la cual la energía de escribir se apoya en el discurso y se separa de él" (28); es la obra como fracaso o imposibilidad que no obstante habita la obra. Dado que la "ausencia de libro" no está en una relación de presencia ni con el libro ni consigo misma, solo puede ser lo que arruina el testimonio y la comunicación, de ninguna manera es lo contrario o lo opuesto al libro.

Oscar del Barco escribe su lectura en el ensayo introductorio a la edición, titulado "Leer Blanchot", y pone un énfasis especial en el hecho de que la ausencia de sentido encarnaría un fin para la ideología de lo propio y por tanto la propiedad: "el afuera, la ausencia de Libro, han roto la clausura de nuestro Sistema, entonces 'todo está permitido', todo es posible, la escritura sin libro, sin autor, sin posesor, despliega su trazo / la revolución / borrando para siempre este Sistema espectral de la propiedad" (del Barco, "Leer Blanchot" 24). Así la ausencia de libro se enlaza en una serie donde la ausencia de autor está en una relación de discontinuidad con la revolución. La barra marca ese trazo que no fija la causalidad ni la mediación,

28 Esta diferencia entre el título (Ausencia del libro) y la fórmula tal como es traducida en el ensayo y recuperada por del Barco en su estudio introductorio ("ausencia de libro") figura así en el original. No hemos precisado aún si se trata solo de un error, o bien hay otros motivos para la variación intitulante. De todos modos, al tratarse de un autor cuya escritura está en el marco de una colección que interroga justamente la différance, voluntario o no, dicho desplazamiento e incongruencia debe ser atendido al menos en lo que respecta sus efectos. 
solo establece un vínculo interrumpido / discontinuo cuya traducción logológica no está dada en el sentido de una representación. En función de una de las hipótesis de este trabajo, es preciso notar que esa ruina del sistema espectral de la propiedad se enlaza en una doble articulación con el ethos editorial de "El hombre y su mundo", porque a la manifestación más concreta de su confrontación - el contrabando de textos y el universo de seudónimos - hay que agregar una dimensión que le es inescindible: el efecto del conjunto Blanchot-revolución como un modo de pensar que ignora la propiedad del sentido y se abre, desde la lengua, a lo im-propio. Si de lo que se trataba era de explorar el dilema "política y revolución", como planteaba J. M. L. en el prólogo a Literatura, política y cambio, en "Leer Blanchot" del Barco pulsa las cuerdas de ese problema, tal vez, de la forma más radical posible rodeando la escritura de blanchotiana con preguntas sobre la revolución y la propiedad. En tanto que ausencia de sujeto, el texto no concierne ni a la historia intelectual de un individuo llamado Maurice Blanchot -asociado con un pasado conservador políticamente-,${ }^{29} \mathrm{ni}$ a la autoridad del Partido en su regulación. ${ }^{30}$

Este movimiento -leer una relación discontinuista entre la escritura de Blanchot, la ausencia de libro y la revolución- constituye una política de la literatura en un doble sentido. Por un lado, es la colección la que funciona saltando los límites de la noción de obra, de propiedad y poniendo en crisis la misma noción de libro ya que el volumen consiste en la reunión de dos ensayos breves tomados sin permiso de las revistas francesas. El libro hace, en tanto inclusión en un catálogo determinado y sus relaciones con otros libros y modos de producción, lo que la lectura del filósofo cordobés le atribuye a la teoría de Maurice Blanchot. Es en una edición sin "propietarios" donde la crítica al Autor como engranaje de un sistema -“"[el] señor que se pasea por todas partes con su nombre propio, que se lo hace pagar de acuerdo con categorías bien definidas, que

29 Cfr.: Cortés, F: “Interrupción y neutro en Maurice Blanchot”. Heterotopias, 3(6), 2020, pp. 118.

30 "La astucia de la razón consiste en resguardar / y conservar / el Sistema modificando los contenidos (en lugar de Dios el dueño del sentido puede llamarse Autor, Creador, Maestro, Patrón, Partido, Gramática, etc.) Salvar el Sistema mediante un mimetismo que conserva su lógica: astucia. La época de la metafísica es la que ha terminado" (del Barco, "Leer Blanchot" 12-13). 
lo convierte en una mercancía estética" (Sollers 34)- se materializa. Del mismo modo que en el libro de Rousseau y Derrida, es la noción de ausencia de obra la que establece una continuidad entre sus escrituras. Pero a su vez, el contrabando de la teoría desborda a su vez los protocolos editoriales de los contratos, la cesión de derechos, pagos, legales y colofones con la información correcta, porque es también un contrabando que sortea las distintas autoridades del texto. Los agentes de la edición serían unas, y los sentidos de la política serían otras.

El ensayo "Leer Blanchot" [1973] fue incluido en La intemperie sin fin (1985), título que del Barco publica desde el exilio mexicano. Allí se reunieron otros textos de la misma época y recorridos similares: "El enigma-Sade" [1969] y "El silencio sobre Bataille" [1970] a propósito de la edición en español de Documents (1970 Monte Ávila), aparecidos en la revista Los libros; y “Antonin Artaud"-introducción a Textos revolucionarios 1923-1946 (Artaud 1972, Ediciones Caldén). Silvio Mattoni advierte que estos ensayos plantean "por momentos una teoría de la escritura. O más bien la escritura es pensada allí como una práctica material que impugna el funcionamiento normal del Sistema" (9). Lo que del Barco nombra como "Sistema" alude a "la estructura piramidal del sentido, o la metafísica [que] implicarían siempre un punto dominante, un centro"; una teoría de la escritura como la que propone es entonces una teoría donde la noción de autor -como origen y fuente del sentido, continúa Mattoni- resulta conmovida en tanto ella manifiesta uno de los residuos de la metafísica de la presencia. $^{31}$

31 Esta conmoción supone la ausencia de sujeto, y la experiencia de desposesión de sí ante la pregunta de quién habla en la escritura, antes que la "muerte del autor": "Algunas frases de Stéphane Mallarmé, quien siempre habría intentado pensar el espacio de la escritura, aparecen y se reiteran, o son aludidas, en los ensayos de Del Barco. Sin ellas, sin el misterio de esos preceptos mallarmeanos, sería muy simple decretar una supuesta "muerte del autor". que incluso podría pensarse como exterior al espacio literario, ocasionada por la repetición de una industria de la literatura donde cada nombre sólo es una función intercambiable. Pero si el "autor" fuera sencillamente "mortal", si pudiera morir, ya sería ese cuerpo discontinuo de alguien, fechado, nombrado, arrojado al desgaste, sería algo material. Cuando Mallarmé dice: quien realiza íntegramente la práctica de la escritura se suprime, quiere decir que ese practicante, ese oficiante, se autolimita, pierde la propiedad de sí mismo que lo ataba a la repetición banal de todo, olvida expresarse, se da un campo de experimentación verbal para que la iniciativa no surja del mero individuo" (Mattoni 10). 
Silvio Mattoni reconoce esa procedencia situada de los ensayos que darían lugar una teoría de la escritura, y señala breves momentos de reformulación entre los ensayos publicados en los 70 y su inclusión en La intemperie sin fin, donde aparecen "diferencias significativas" en el ámbito de la "política" y la "poética". Toma dos ejemplos, uno de ellos directamente vinculado con lo que acá tratamos de explicar como política de la teoría:

En 1973, el ensayo "Leer Blanchot” preguntaba: “Cómo pensar al margen de los movimientos populares, de las mareas revolucionarias?" Mientras que en el libro, en un pasaje que hemos citado, se interroga de este otro modo: “¿Cómo pensar al margen de las constantes mareas que relanzan lo propio a lo indeterminado, a órdenes disímiles, a espejos?” De alguna manera, la primera pregunta supondría cierta ingenuidad o referencialismo porque parece identificar la violencia de la escritura, la irrupción del trazado material en la esfera del sentido, con una violencia física, circunstancial, y cuya ilusión teleológica no haría sino prolongar la escisión entre materia y significación. También resulta más coherente con una presentación del pensamiento de Blanchot la segunda forma de la pregunta sobre lo inapropiable de la escritura. En general, este revisionismo, por llamarlo de algún modo, que altera sólo algunas frases, se traduce en la opción ética de una transformación real, de la materia y del lenguaje, antes que una adhesión a la marea histórica como algo dado, un proceso en curso, y que es un dato que además esconde en su aspecto de repetición masiva un elemento siniestro. (Mattoni 24)

En efecto, la palabra "revolución" tiene, como ya vimos, en el ensayo introductorio a la escritura de Blanchot, un peso disonante y grave respecto de aquello que "coherentemente" -siguiendo el término que utiliza Mattonisupondría leer al autor francés. Ahora bien, siguiendo la hipótesis inicial de Mattoni y estos momentos donde la escritura situada se despega del campo de 
fuerzas hacia donde se vería atraída, es posible advertir que esta teoría de la escritura -la que pone en cuestión al Sistema y con él a las nociones de autor y lector-hace parte, en la primera versión de los ensayos, de una serie de prácticas editoriales por las que es atravesada y definida. Es precisamente por ese momento donde la coherencia se quiebra $-\mathrm{y}$ no a pesar de él-, que formulamos la relación entre teoría y edición en "El hombre y su mundo" como una política de la teoría, ya que se trata de una disonancia que vuelve doblemente extraño el peso de lo político: respecto del texto que comenta, y respecto del modo en que la política era hablada y pensada en los años 70 .

La teoría de la escritura que del Barco persigue en los textos que escribe y aquellos que lee y traduce aloja esa disonancia en la posibilidad de juntar a Blanchot con las mareas revolucionarias, o a Sartre con Derrida. Así, el encuentro de lo heterogéneo, lo que no podría estar junto, produce un efecto político sobre la materialidad de una edición contrabandista. ${ }^{32} \mathrm{El}$ espesor político diferencial respecto del programa francés con el que dialoga y al que refiere ${ }^{33}$ puede leerse entonces en el pliegue entre formas de establecer conjuntos y prácticas editoriales que hacen de la puesta en circulación un acto de la teoría. En el catálogo de "El hombre y su mundo", la "mezcla", el "fárrago" y el rigor teórico que pretende conjurar el eclecticismo se articulan sin integrarse, de modo tal que la noción de teoría es conmovida por el tipo de apropiación de los conceptos por parte de la editorial.

El uso de la teoría que hace del Barco y su puesta en libro nos permite pensar en lo que Judith Podlubne llamó, a propósito del fin de la teoría, como "experimentación con el tenor performativo del concepto": "el encuentro con el

32 El catálogo de "El hombre y su mundo" puede pensarse, en ese sentido, como un avatar más de lo que Diego Peller pensó en Pasiones teóricas. Crítica y literatura en los setenta, como la posibilidad de leer a Rodolfo Walsh en relación con o junto a Oscar Massota, donde más allá de las trayectorias individuales de cada escritor, lo que proponía esa conjunción era una vía más amplia y múltiple acerca de los modos de articular literatura y política por fuera de los puntos de contacto más esperables: la ideología, el compromiso, la representación

33 Un aspecto que Raúl Antelo ha pensado en términos de "modernidad de los pobres y dependientes que redefine la modernidad como universalidad desde una actividad de inercia traducida como energía diferencial o transgresiva" (Antelo, "Transgressão" 16). 
punto en que ese tenor excede la convención y vuelve infinitas sus posibilidades de significar" (88), para referirse a la inseguridad semántica constitutiva en el término teoría:

La teoría literaria no es una forma de conocimiento, una trama categorial específica y sofisticada a disposición de una sustancia preexistente, explicable y expandible, sino el modo, cada vez único, en que el saber experimenta la fecundidad de su falta. (Podlubne, 88)

Esa búsqueda del rigor teórico -que del Barco despliega en sus intervenciones más polémicas- y que procuraba ejercer el discernimiento en lucha "contra los eclecticismos", ${ }^{34}$ echó mano a una serie de escrituras que mostraron la ruptura -esa que vibraba en la posibilidad de "tirar abajo las estructuras del capital y la burguesía", la "demolición del hermoso edificio ideológico-lingüístico" de la sociedad capitalista, la destrucción del sentido, la comunicación y la unicidad del "yo" creador-; Lautréamont, Mallarmé, Rimbaud, Artaud, Bataille son esas "desgarraduras". ${ }^{35}$ Ahora bien, son estas mismas escrituras las que ponen cada vez a tambalear a la teoría que buscaba pensarlas. En ese sentido, es del Barco tal vez, quien advierte -aún sin saberlo- esa "falta originaria" de la teoría, que la destina a todo fracaso (Podlubne, 88), la vuelve subversiva y efectúa una "reflexión teórica" en el sentido de lo que arroja "siempre un «residuo de indeterminación» que retorna transfigurado en conceptualizaciones futuras. Ese retorno dota al saber teórico del carácter impredecible que lo distingue y define así la forma de su temporalidad" (Podlubne, 88). Es en esa temporalidad singular del montaje de heterogéneos y la

34 Sin duda esta búsqueda de supresión de todo espectro de eclecticismo que amenazara el regreso de las mistificaciones representacionales forma parte de una arqueología vanguardista de la teoría, en tanto fueron las vanguardias históricas las que también buscaron, tiempo atrás, la destrucción de todo resto de semblante figurativo. Un abordaje de este problema fue tratado, siguiendo a Alain Badiou (2011) en Verónica Stedile (2020), "Síntesis, depuración y restos espectrales: la imagen surrealista e invencionista en las revistas argentinas de mediados de siglo".

35 "El discurso económico logocéntrico analiza el valor poniendo el acento en el cambio: el producto vale -fundamentalmente- en el mercado, donde el signo que lo representa es la moneda. Desgarradura Marx / desgarradura Freud / desgarradura Nietzsche / desgarradura Sade / desgarradura Mallarmé / desgarradura Lautréamont" (J. M. L.). 
puesta en acto de la teoría a partir de los modos de publicación donde puede leerse una política de la teoría.

\section{Bibliografía}

Aguado, Amelia. "La consolidación del mercado interno (1956-1976)". En: José Luis de Diego (dir.) Editores y políticas editoriales en Argentina (18802010). Fondo de Cultura Económica, 2014, 135 - 173.

Antelo, Raúl. "Transgressão e estudos culturais". Transgressão e modernidade. Editora UEPG, 2001. . Crítica acéfala. Sala Grumo, 2008.

Artaud, Antonin. Textos revolucionarios 1923 - 1946. Ediciones Caldén, 1972.

Barbeito, Ignacio. "Ediciones Nagelkop, Aula Vallejo e Igitur. Aportes para una Historia del Circuito Editorial en la Córdoba de los '60s y primeros '70s”. Políticas de la Memoria, n10/11/12, 2009-2011, pp. 143- 148.

Barthes, Roland; Guyotat, Pierre; Henric, Jacques.; Sollers, Philippe. Literatura, política y cambio. Ediciones Caldén, 1976.

Barthes, Roland; Kristeva, Julia; Thibaudeau, Jean. El proceso de la escritura. Ediciones Caldén, 1974.

Bataille, Georges. Las lágrimas de Eros. Signos, 1968. . Breve historia del erotismo. Ediciones Caldén, 1976.

Blanchot, Maurice. La ausencia del libro. Nietzsche y la escritura fragmentaria. Ediciones Caldén, 1973.

Bugnone, Ana. La revista Hexágono '71 [1971-1975]. Biblioteca Orbis Tertius y Centro de Arte Experimental Vigo, 2014.

Brecht, Bertolt; Grosz, Geroge; Piscator, Erwin. Arte y sociedad. Ediciones Caldén, 1968.

Cortés, Federico. "Interrupción y neutro en Maurice Blanchot". Heterotopias, 3.6, diciembre de 2020, pp. 1-18.

del Barco, Oscar. "Leer Blanchot". Maurice Blanchot. La ausencia del libro. Nietzsche y la escritura fragmentaria. Ediciones Caldén, 1973, pp. 7- 24. . "Polémica. Respuesta a 'Puntos de partida para una discusión". Los Libros 3.22, septiembre de 1971, p. 32. . Presentación a El proceso de la escritura, R. Barthes; J. Kristeva; J. Thibaudeau. Ediciones Caldén, 1974.

Derrida, Jacques.; Rousseau, Jean Jacob. La lingüística de Rousseau. El origen de las lenguas. Ediciones Caldén, 1970. 
García, Diego. "Signos. Notas sobre un momento editorial". Políticas de la Memoria, n 10/11/12, 2009-2011, pp. 149-158.

. ¿De la ilustración a la revolución? Apuntes sobre la actividad editorial de Pasado y Presente". Prismas - Revista de Historia Intelectual 18, junio de 2014, pp. 209-215.

Lafforgue, Jorge. "Bertolt Brecht". Los libros, 1.2, agosto de 1969, p. 5.

Mangieri, José Luis. Es rigurosamente cierto. Libros del Rojas, 2004.

Mattoni, Silvio. "Sobre el acto de la escritura". AA.VV. El fragor del mundo. Escritos para Oscar del Barco. Alción editora, 2008, 9-25.

Klee, Paul. Teoría del arte moderno. Ediciones Caldén, 1971.

Peller, Diego. Pasiones teóricas. Crítica y literatura en los setenta. Santiago Arcos, 2016.

Podlubne, Judith. (2017). "La edad de la teoría literaria". Dossier Fin y resistencia de la teoría. El Taco En La Brea. 1.5, mayo de 2017), pp. 83-94. https://doi.org/10.14409/tb.v1i5.6617

Rancière, Jacques. Política de la literatura. Libros del Zorzal, 2011. Traducción: Marcelo G. Burello, Lucía Vogelfang, J.L. Caputo.

Vanoli, Hernán. 'La 'tradición independiente' en la edición literaria argentinasexual y la inclusión en el consumo mediante la estrategia "gay friendly" [en línea]. IX Jornadas de Sociología. Facultad de Ciencias Sociales. Buenos Aires: Universidad de Buenos Aires, 2011. Disponible en: https://www.aacademica.org/000-034/12 (visitado el 22/04/2021)

Wolff, Jorge. Telquelismos latinoamericanos. La teoría crítica francesa en el entre-lugar de los trópicos. Grumo, 2009.

Yuszczuk, Marina. Lecturas de la tradición en la poesía argentina de los noventa [en línea]. Tesis de posgrado. Universidad Nacional de La Plata. Facultad de Humanidades y Ciencias de la Educación, 2011. Disponible en: http://www.memoria.fahce.unlp.edu.ar/tesis/te.742/te.742.pdf

Williams, Raymond. Marxismo y literatura. Las cuarenta editorial, 2009. Traductor: Guillermo David. 